\title{
BMJ Open Effects of introducing a walk-in clinic on ambulatory care sensitive hospitalisations among asylum seekers in Germany: a single-centre pre-post intervention study using medical records
}

\author{
Celina Lichtl (D) , ${ }^{1,2}$ Kayvan Bozorgmehr ${ }^{1,3}$
}

To cite: Lichtl C, Bozorgmehr K. Effects of introducing a walkin clinic on ambulatory care sensitive hospitalisations among asylum seekers in Germany: a single-centre prepost intervention study using medical records. BMJ Open 2019;9:e027945. doi:10.1136/ bmjopen-2018-027945

- Prepublication history for this paper is available online. To view these files, please visit the journal online (http://dx.doi. org/10.1136/bmjopen-2018027945)

Received 15 November 2018 Revised 23 September 2019 Accepted 04 November 2019

D Check for updates

(c) Author(s) (or their employer(s)) 2019. Re-use permitted under CC BY-NC. No commercial re-use. See rights and permissions. Published by BMJ.

For numbered affiliations see end of article.

\section{Correspondence to}

Prof Dr Kayvan Bozorgmehr; kayvan.bozorgmehr@med.uniheidelberg.de

\section{ABSTRACT}

Objective Measuring the effect of introducing a walk-in clinic on ambulatory care sensitive (ACS) hospitalisations among asylum seekers in a large state reception- and registration centre.

Design and setting Pre-post intervention study using anonymous account data from a university hospital functioning as referral facility for a state reception- and registration centre in the third largest German federal state.

Participants We included all asylum seekers residing in the reception centre and admitted to the referral hospital between 2015 to 2017.

Interventions Establishment of an interdisciplinary walkin clinic in the reception centre (02/2016).

Main outcome measures International lists for ACS conditions for both adults and children were adapted and used to calculate the prevalence of ACS conditions among the population (primary outcome measure). The impact of the intervention on the outcome was analysed using a segmented Poisson regression to calculate incidence-rate ratios with respective $95 \%$ Cls, adjusted for age, sex and admission.

Results The prevalence of ACS hospitalisations changed over time, as did the effect of age, sex and quarter of admission. Introducing the walk-in clinic reduced the prevalence of ACS hospitalisations among asylum seekers compared with the period before establishment of the clinic (incidence-rate ratios $(\mathrm{IRR})=0.80(0.65$ to 1.00$)$, $p=0.054)$, but the effect was attenuated after adjustment for time trends. The average difference in prevalence of ACS hospitalisations compared with the period before establishment of the clinic, corrected for pre-existing time trends, age and sex of asylum seekers was IRR $=1.03$ ((0.69 to 1.55), $p=0.876)$.

Conclusions A walk-in clinic in reception centres may be effective to reduce ACS hospitalisations, but our study could not prove evidence for a measurable effect after full adjustment for time trends. Further research, ideally with parallel control groups, is required to establish evidence for the effectiveness of walk-in clinics in reception centres on reducing ACS hospitalisations.
Strengths and limitations of this study

The study uses the introduction of a walk-in clinic as quasi-experimental design to measure and quantify the effects of the organisational-level intervention on ambulatory care sensitive (ACS) hospitalisations among asylum seekers.

- It quantifies the effect of health service delivery designs among asylum seekers, adjusting for time trends and individual-level characteristics of the underlying population.

- The study allows the evaluation of the effectiveness of the walk-in clinic by using objective parameters of primary care quality.

- Analysis is limited by various factors and influences on hospitalisation for ACS conditions, which are outside of the control of the ambulatory sector and difficult to adjust for.

- Lack of concurrent control sites and important individual-level data hamper generalisability.

\section{BACKGROUND}

The measurement of strength, access and quality of ambulatory care and evaluation of primary care policies has proved to be a complex undertaking. The concept of ambulatory care sensitive (ACS) hospitalisations has increasingly been used to examine ambulatory and primary care. ${ }^{12}$ Billings $e t$ $a l^{3}$ initially defined ACS conditions as conditions for which the provision of timely and effective outpatient care can help to reduce the risks of hospitalisation by either preventing the onset of an illness or condition, controlling an acute episodic illness or condition or managing a chronic disease or condition'. The concept of ACS hospitalisations is therefore based on the supposition, 
that certain conditions and thus hospitalisations may be prevented by the timely appropriate ambulatory care outside the hospital. ${ }^{4}$

The provision of timely ambulatory care is particularly challenging for asylum seekers. In Germany, only 'necessary medical or dental treatment of acute illness and pain, including the provision of medication and bandages and necessary measures for convalescence, recovery or alleviation of disease or necessary services addressing consequences of illnesses' ${ }^{1}$ are covered, as regulated by the Asylum Seekers' Benefits Act ('Asylbewerberleistungsgesetz'). Vaccination, necessary preventive medical check-ups and pregnancy- and childbirth care are also to be provided. Not only does initial restriction of access to care for refugees and asylum seekers lead to delayed care, it leads to costly treatment and increases health expenditures per asylum seeker. ${ }^{5}$ Healthcare in German reception centres is often provided on an irregular basis ${ }^{6}$ and practical barriers increase the challenges in access to healthcare: lack of familiarity with the healthcare system and accordingly low use of entitlements, ${ }^{7}$ inadequate information and communication, limited access to transport and inadequate provision of interpreters. ${ }^{8}$

There is a vast heterogeneity in healthcare for asylum seekers in Germany due to decentralised organisation and responsibilities. ${ }^{9-11}$ Due to the lack of nationwide standards, federal regulations determine the content and implementation of health examination policies and ${ }^{10}$ the organisation of care for asylum seekers. In consequence, regulations differ strongly among the different German states. Attempts to evaluate the different models of healthcare provision ${ }^{9}$ are yet again challenged by both the exclusion of asylum seekers from routine health monitoring systems in Germany ${ }^{12}{ }^{13}$ and limited methodological approaches to objectively compare different models with respect to their performance.

In this study, we used the concept of ACS conditions and hospitalisations to examine the impact of introducing a walk-in clinic in a large state reception- and registration centre for asylum seekers in a German city on preventable hospitalisations among this population.

\section{METHODS}

\section{Context and setting}

In September 2015, the reception centre for refugees in Heidelberg-Kirchheim in the former US Army installation 'Patrick Henry Village' was converted into the first 'state reception- and registration centre' ('Zentrale Erstregistrierungsstelle') for the state of Baden-Württemberg. Initially, the reception centre, set up in December 2014, had functioned as a temporary reception centre due to high immigration flows ('Bedarfsorientierte Erstaufnahmestelle') with around 900 residents. ${ }^{14}$ The numbers rose to nearly $2600^{15}$ in July 2015 and more than 6500 in August 2015. Medical care was provided by a commercial health services agency; however, the availability of medical professionals was limited to 4 hour visits from a general practitioner. The average stay of refugees in the centre was estimated between 3 and 6 months. After the reorganisation of the reception centre to the state reception- and registration centre, the average stay was reduced to about 4 to 8 weeks in February 2016 (personal communication with state authorities). Since the peak in August 2015, the number of residents in the Patrick Henry Village had gradually fallen to around 1500 in June $2018,{ }^{16}$ corresponding with an overall decrease of asylum applicants in the federal state. ${ }^{17}$ The state reception- and registration centre is responsible for the primary registration of arriving asylum seekers, the medical examination, tuberculosis screening via chest X-ray and the submission of asylum applications - and in some cases also for the direct decision of said applications. The further transfer to decentralised accommodation or other processing points depends on the asylum decision or prognosis of it. In reception centres, the costs for healthcare for asylum are covered by the respective federal state's administrative regional council ('Regierungspräsidium'). In collective accommodation centres and decentralised accommodation, the social welfare office of the respective district is responsible for these costs.

To increase the availability and quality of healthcare to asylum seekers, Heidelberg University Hospital together with local resident physicians established a walk-in clinic on-site in February 2016. ${ }^{18}$ Consultations are offered in the fields of general medicine, gynaecology, paediatrics, tropical medicine and psychiatry/psychosomatic medicine for both the treatment of acute illnesses and preventive medical check-ups. The hospital has been functioning as main reference and referral facility for hospitalisations both before and after the introduction of the walk-in clinic. ${ }^{9} 19$

\section{Design}

The introduction of the walk-in clinic constitutes a nonrandomised organisational-level intervention. Using medical records of Heidelberg University Hospital, we exploited the quasi-experimental nature of the introduction to evaluate the effects on ACS hospitalisations in a pre-post design with non-concurrent control groups. Our reporting guideline for this study design was the TIDieR-PHP Checklist for population health and policy interventions $^{20}$ (see online supplementary file 1 ). The records include all patients, which were admitted to the hospital for inpatient care over a 2 year period (01 January 2015 to 31 December 2017).

\section{Data collection and participants}

We received anonymous account data from the accounts department of Heidelberg University Hospital on all patients admitted to inpatient care in the hospital in the years 2015 to 2017. The data set contained information on age at admission, sex, date of admission and discharge, patient- and case numbers, specialist organisational units, nursing organisational units, the patient's cost unit, primary and secondary diagnoses, Diagnosis 
Related Group case payments and diagnosis codes according to the International Classification of Diseases (ICD). All patients admitted to inpatient care at Heidelberg University Hospital between 01 January 2015 and 31 December 2017 with a unique cost unit for asylum seekers in state-mandated reception centres were included in our study. Patients with this cost unit were classified as asylum seekers, as it distinctly identifies refugees who are accommodated in reception centres under federal state mandate. Other cost units were thus excluded, since these do not provide information on residence status.

\section{Measuring ambulatory care sensitive hospitalisations}

A number of international studies have established lists of ACS conditions for both adults and children. ${ }^{21-27}$ Mostly these have been developed on the basis of expert consensus procedures or by analysis of discharge records. ACS conditions for children were operationalised following an approach which we applied in a previous study. ${ }^{28}$ The approach synthesised seven international studies, ${ }^{21-27}$ which had identified and validated paediatric ACS conditions. ACS conditions validated in at least three international studies were included in the final list. Three further conditions (allergies and allergic reactions, gastritis and neonatal jaundice) were added manually based on the expertise of local paediatricians. ${ }^{28}$ The final list of ACS conditions among children thus comprised 17 conditions: (1) Allergies and allergic reactions, (2) Asthma, (3) Convulsions, (4) Dental conditions, (5) Diabetes mellitus, (6) Failure to thrive, (7) Gastritis, (8) Gastroenteritis/dehydration, (9) Immunisationpreventable diseases, (10) Inflammatory diseases of female pelvic organs, (11) Iron deficiency anaemia/ anaemia, (12) Kidney- and urinary infections, (13) Nutritional deficiency, (14) Neonatal jaundice, (15) Severe ear, nose and throat (ENT) infection, (16) Skin infection, (17) Doctor's orders have not been followed by patient.

Furthermore, we used a list of ACS conditions for adults in Germany, ${ }^{29}$ which was established by 40 physicians in a three-round Delphi survey and consists of 22 codes: (1) Ischaemic heart diseases, (2) Heart failure, (3) Other diseases of the circulatory system, (4) Bronchitis and chronic obstructive pulmonary disease, (5) Mental and behavioural disorders due to the use of alcohol or opioids, (6) Back pain (dorsopathies), (7) Hypertension, (8) Gastroenteritis and other diseases of intestines, (9) Intestinal infectious diseases, (10) Influenza and pneumonia, (11) Ear, nose and throat infections, (12) Depressive disorders, (13) Diabetes mellitus, (14) Gonarthrosis (arthrosis of knee), (15) Soft tissue disorders, (16) Other avoidable mental and behavioural disorders, (17) Diseases of the eye, (18) Diseases of the urinary system, (19) Sleep disorders, (20) Diseases of the skin and subcutaneous tissue, (21) Malnutrition and nutritional deficiencies, (22) Dental diseases.

All diagnoses were categorised into a dichotomous variable according to the lists of adult and children's ACS conditions, indicating whether or not an incident hospitalisation is considered as preventable.

\section{Data analysis}

The descriptive analysis includes calculation of period means and SD for interval-scaled variables (age) and proportions for dichotomous (sex, ACS hospitalisation) and categorical variables (age groups, comprising under 1 year of age, 1 to 9 years, 10 to 19 years, 20 to 29 years, 30 to 39 years, 40 to 49 years, 50 to 59 years and $>60$ years) stratified by year. Scatter plots were used to analyse change in ACS hospitalisations over time descriptively.

To assess potential changes over time in differences in ACS hospitalisations between male and female asylum seekers, and between asylum seekers in different age groups, we performed a univariate logistic regression analysis for each year. We analysed the effect of sex, age (collapsed into a dichotomous variable comparing adults aged 18 years and above with children below the age of 18) and the quarter of admission respectively on ACS hospitalisations each year in a repeated cross-sectional design and calculated ORs and 95\% CIs.

We then conducted a segmented Poisson regression and examined the incidence-rate ratios (IRR) with respective $95 \%$ CI, adjusted for age, sex and admission before/after establishment of the walk-in clinic. We used the natural $\log$ transformation (ln) of the rate and an iterative process to produce an estimated regression equation $^{30}$ as follows: $\ln (\mathrm{r})=a+\mathrm{b} 1 \times \mathrm{AGE}+\mathrm{b} 2 \times \mathrm{SEX}+\mathrm{b} 3 \mathrm{x}$ $\mathrm{PHV}+\mathrm{b} 4 \mathrm{x}$ PRE-PHV + b5 x POST-PHV (Equation 1)

In this model, $a$ is the estimated constant term providing an estimate of the $\log$ rate when all explanatory variables take the value 0 and the estimated Poisson regression coefficients are $b 1$ to $b 6 .^{30}$ AGE is an explanatory categorical variable with two groups (adults aged 18 years and above and children below the age of 18) and SEX is a binary variable coded 1 for female and 0 for male. The variable 'PHV' is a time-dependant variable, which codes 0 before the establishment of the clinic (January 2015 to January 2016) and sequentially 1 from there on (February 2016 to December 2017), thus dividing the population into an experimental group residing in the reception centre after introduction of the walk-in clinic (coding 1) and a non-randomised, non-concurrent control group residing in the reception centre prior to its introduction (coding 0 ). We generated two further variables 'PRE-PHV' and 'POST-PHV' for the segmented regression, both also being time-dependant variables specific for the period before and after the establishment of outpatient care in the reception centre Patrick Henry Village (PHV). Our data elapses over 36 months in total, PRE-PHV coding 1 to 13 equivalent to the 13 months of patient admission before the establishment of the walk-in-clinic and coding 13 for the months thereafter (February 2016 and later). POST-PHV codes 0 until January 2016 and 1 to 23 for the months of admission, in which the walk-in clinic was operating (the remaining 23 of the overall 36 months). These variables measure the average change in level of 
outcome in the PRE-PHV period compared with the postreform period, corrected for pre-existing trends. The rationale for this is to adjust different forms of bias, that can occur in longitudinal analysis of routine data, such as non-stationarity, auto-correlation and seasonality. ${ }^{31} \mathrm{We}$ also performed an explorative subgroup analysis using each of the most frequent ACS conditions as outcome in adjusted segmented Poisson regression models according to Equation 1 (instead of an variable for overall ACS hospitalisations). The final Poisson models were chosen after ruling out overdispersion by comparing them with a negative binomial regression model (likelihood ratio test of alpha $=0$ not statistically significant at the 0.05 level). A sensitivity analysis with age as a continuous predictor in comparison to age being dichotomous was performed. All analyses were performed using Stata V.15.1.

\section{RESULTS}

\section{Descriptive results}

Between 01 January 2015 and 31 December 2017, a total of 1152 asylum seekers were admitted to hospital resulting in 1383 admissions (ie, hospital cases). Of these, $641(46.3 \%)$ were male and $742(53.7 \%)$ were female. A marked increase in women from $43.5 \%$ in 2015 to $63.5 \%$ in 2017 and a consequent decrease in men was observed. The largest age group both overall and in each year separately was that of 20 to 29 year olds, comprising 390 patients $(28.2 \%)$. The percentage of patients in this age group increased from $20.5 \%$ in 2015 to $33.7 \%$ in 2017 . Of the 1383 hospital admissions, 410 of these hospital cases were treated before the introduction of the walk-in clinic in February 2016 and 973 cases were treated afterwards. The overall number of patients hospitalised in the year $2017(\mathrm{n}=597)$ was 1.6 times the number treated in 2015 $(\mathrm{n}=375)$. Overall, 148 admissions $(10.7 \%)$ were hospitalised for an ACS condition (primary diagnosis coded as ACS condition). The percentage of hospitalisations for ACS conditions among all hospitalisations among asylum seekers declined by $50 \%$ in the observation period (from $15.7 \%$ in 2015 to $10.2 \%$ in 2016 and $7.9 \%$ in 2017). Among adults, the most common ACS conditions were 'other avoidable mental and behavioural disorders' $(2.7 \%)$, 'mental and behavioural disorders due to use of alcohol or opioids' $(0.6 \%)$, 'diabetes mellitus' $(0.6 \%)$ and 'ischaemic heart diseases' $(0.6 \%)$. Among children, the most prevalent ACS conditions were 'immunisationpreventable diseases' $(0.9 \%)$ and 'severe ENT infections' $(0.9 \%)$. The descriptive results can be seen in table 1 .

\begin{tabular}{|c|c|c|c|c|}
\hline & 2015 & 2016 & 2017 & Total \\
\hline & $\begin{array}{l}\text { Freq. } \\
\text { (Col \%) }\end{array}$ & $\begin{array}{l}\text { Freq. } \\
\text { (Col \%) }\end{array}$ & $\begin{array}{l}\text { Freq. } \\
\text { (Col \%) }\end{array}$ & $\begin{array}{l}\text { Freq. } \\
\text { (Col \%) }\end{array}$ \\
\hline \multicolumn{5}{|l|}{ Sex } \\
\hline Male & $212(56.5)$ & $211(51.3)$ & $218(36.5)$ & 641 (46.3) \\
\hline Female & $163(43.5)$ & $200(48.7)$ & $379(63.5)$ & $742(53.7)$ \\
\hline Total & $375(100.0)$ & $411(100.0)$ & 597 (100.0) & $1383(100.0)$ \\
\hline \multicolumn{5}{|l|}{ Age groups } \\
\hline$>60$ years & $6(1.6)$ & $1(0.2)$ & $11(1.8)$ & $18(1.3)$ \\
\hline $50-59$ years & $9(2.4)$ & $12(2.9)$ & $10(1.7)$ & $31(2.2)$ \\
\hline $40-49$ years & $30(8.0)$ & $22(5.4)$ & $21(3.5)$ & $73(5.3)$ \\
\hline $30-39$ years & $62(16.5)$ & $54(13.1)$ & $92(15.4)$ & $208(15.0)$ \\
\hline 20-29 years & 77 (20.5) & $112(27.3)$ & $201(33.7)$ & 390 (28.2) \\
\hline 10-19 years & $56(14.9)$ & $66(16.1)$ & $48(8.0)$ & 170 (12.3) \\
\hline $1-9$ years & $65(17.3)$ & $56(13.6)$ & $47(7.9)$ & $168(12.1)$ \\
\hline$<1$ year of age & $70(18.7)$ & $88(21.4)$ & $167(28.0)$ & $325(23.5)$ \\
\hline Total & $375(100.0)$ & $411(100.0)$ & $597(100.0)$ & $1383(100.0)$ \\
\hline \multicolumn{5}{|c|}{ ACS hospitalisations } \\
\hline No & 316 (84.3) & $369(89.8)$ & $550(92.1)$ & $1235(89.3)$ \\
\hline Yes & $59(15.7)$ & $42(10.2)$ & $47(7.9)$ & $148(10.7)$ \\
\hline Total & $375(100.0)$ & $411(100.0)$ & $597(100.0)$ & $1383(100.0)$ \\
\hline
\end{tabular}

ACS, ambulatory care sensitive; Col \%

, column percentage

; Freq, absolute frequency 


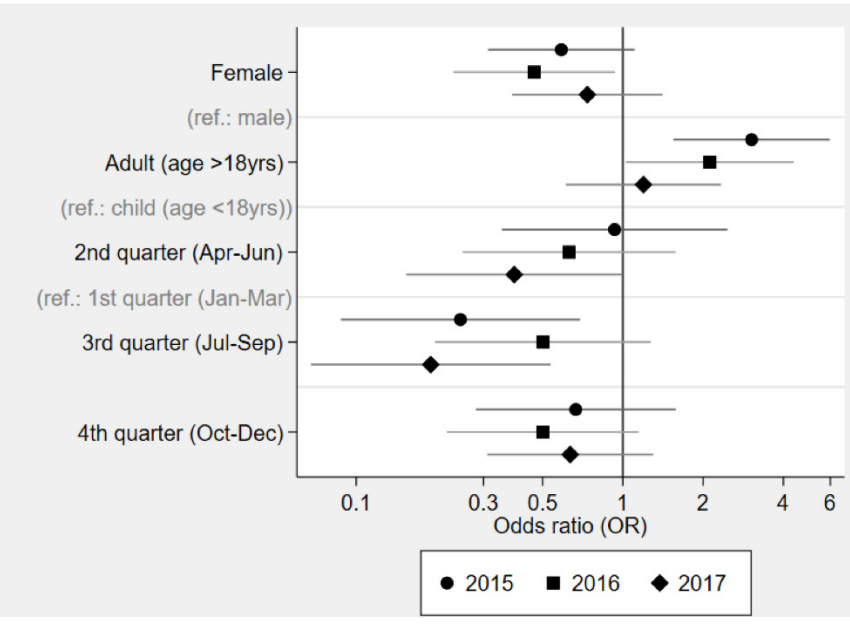

Figure 1 Effects of sex, age and quarter of admission on ambulatory care sensitive hospitalisations by year, $n=1367$ asylum seekers.

\section{Effect of age, sex and quarter of admission on ACS hospitalisations}

In the year 2015, the chance of an adult being hospitalised for an ACS condition was more than four times than that of a child under the age of $18(\mathrm{OR}=4.11 ;(1.85$ to 9.13); $p=0.001)$. In the years 2016 and 2017, the difference in odds of hospitalisation between adults and children declined. Female asylum seekers tended to have lower odds of ACS hospitalisations compared with male. No significant yearly differences with regard to quarterly admission could be detected. A certain seasonal pattern could be identified: hospitalisations for ACS conditions were highest in the first quarter of the year throughout the observation period (see figure 1).

\section{Adjusted segmented poisson regression estimates}

In the fully adjusted model (Model 5 ), hospitalisation for ACS conditions for adults was 2.08 times (1.61 to 2.69) the incident events of children (table 2). The incidence rate of women being hospitalised for ACS conditions was 0.64 times $(0.52$ to 0.79$)$ that of men. These estimates were stable in size and direction in all mutually adjusted models (see Models 2 to 5, table 2). Introducing the walk-in clinic reduced the prevalence of ACS hospitalisations among asylum seekers compared with the period before establishment of the clinic (IRR $=0.80$ ( 0.65 to $1.00), \mathrm{p}=0.054)$, but the effect was attenuated after adjustment for time trends. The average difference in prevalence of ACS hospitalisations compared with the period before establishment of the clinic, corrected for preexisting time trends, age and sex of asylum seekers was $\mathrm{IRR}=1.03$ ( 0.69 to 1.55 ); $\mathrm{p}=0.876$ (table 2 ). Using age as continuous variable affected neither strength nor direction of the associations (data not shown).

\section{Adjusted subgroup regression estimates}

The most frequent ACS conditions were: (1) avoidable mental and behavioural disorders, (2) immunisationpreventable diseases, (3) severe ENT infections, (4) mental and behavioural disorders due to use of alcohol or opioids, (5) diabetes mellitus and (6) ischaemic heart diseases. Using these in explorative subgroup analysis as outcomes instead of overall ACS hospitalisations did not show statistically significant changes in outcomes over time (data not shown).

\section{DISCUSSION}

\section{Statement of principal findings}

In this study, we used the concept of ACS hospitalisations as an indicator to measure the effect of introducing a

Table 2 Regression estimates for hospitalisation for ACS conditions after versus before introduction of the walk-in clinic onsite, $n=1376$ admissions

\begin{tabular}{|c|c|c|c|c|c|}
\hline \multirow[b]{2}{*}{ Explanatory variables } & Model 1 & Model 2 & Model 3 & Model 4 & Model 5 \\
\hline & \multicolumn{5}{|c|}{ IRR, $(95 \% \mathrm{Cl}), \mathrm{p}$ value } \\
\hline \multicolumn{6}{|l|}{ Age group } \\
\hline \multicolumn{6}{|l|}{ Sex } \\
\hline Female (Ref.: male) & & $\begin{array}{l}0.61(0.49 \text { to } 0.75) \\
<0.0005\end{array}$ & $\begin{array}{l}0.63(0.51 \text { to } 0.77) \\
<0.0005\end{array}$ & $\begin{array}{l}0.63(0.51 \text { to } 0.77) \\
<0.0005\end{array}$ & $\begin{array}{l}0.64(0.52 \text { to } 0.79), \\
<0.0005\end{array}$ \\
\hline $\begin{array}{l}\text { Change in level of outcome (after } \\
\text { vs before introduction of walk-in } \\
\text { clinic) }\end{array}$ & & & $\begin{array}{l}0.80 \text { (0.65 to } 1.00) \\
0.054\end{array}$ & $\begin{array}{l}0.86(0.61 \text { to } 1.22) \\
0.399\end{array}$ & $\begin{array}{l}1.03(0.69 \text { to } 1.55), \\
0.876\end{array}$ \\
\hline $\begin{array}{l}\text { Average time trend before } \\
\text { introduction }{ }^{*}\end{array}$ & & & & $\begin{array}{l}0.99 \text { (0.92 to } 1.05) \\
0.680\end{array}$ & $\begin{array}{l}0.99 \text { (0.92 to } 1.05), \\
0.668\end{array}$ \\
\hline $\begin{array}{l}\text { Average time trend after } \\
\text { introductiont }\end{array}$ & & & & & $\begin{array}{l}0.99(0.97 \text { to } 1.00), \\
0.100\end{array}$ \\
\hline
\end{tabular}

${ }^{*}$ refers to the time period before the establishment of the outpatient clinic (01/2015 to 01/2016).

trefers to the time period after the establishment of the outpatient clinic (02/2016 to 12/2017).

ACS, ambulatory care sensitive; IRR, incidence-rate ratios; Ref., reference. 
walk-in clinic on-site in a state reception- and registration centre for asylum seekers. Initially, the establishment of the walk-in clinic led to a reduction of the prevalence of ACS hospitalisations among asylum seekers compared with the period before establishment. After adjustment for time trends, this impact could no longer be observed. The results raise a number of questions and points of discussion, which we will discuss below.

As listed above, the overall number of patients hospitalised in the year 2017 is 1.6 times than that of 2015, while the percentage of hospitalisations for ACS conditions among all hospitalisations fell by 50\% between 2015 and 2017. These results indicate that the walk-in clinic has functioned as a 'gate-opener' for asylum seekers, linking patients to needed in-patient care and increasing the percentage of hospitalisations deemed to be not avoidable. Although these descriptive results are in line with the adjusted model before inclusion of time trends, the fully adjusted results of our segmented regression show no such change in the rate of hospitalisations for ACS conditions. There could be different explanations for these observations. First, ACS conditions could be the result of pre-migration and peri-migration structures, thus representing a 'steady state', that is, a constant rate of ACS conditions among asylum seekers, which are outside of the reach of the ambulatory care sector and walk-in clinics in respective destination countries. Testing this assumption would require control sites and more data on ACS conditions and hospitalisations specifically among the refugee-seeking and asylum-seeking population. However, only little data has been published on this topic ${ }^{132}$ and control sites were not available in our specific case. Second, it is possible that the walk-in clinic has not been effective in addressing ACS conditions, for example, due to limitations of the specific care model and related challenges in the organisation of care. ${ }^{9}$ These aspects, however, cannot be addressed by our data. Another explanation for the results of our study could be the healthseeking behaviour and healthcare utilisation among asylum seekers, ${ }^{733} 34$ such as possible circumvention of the walk-in clinic, avoidance of primary care or seeking of medical care at a later stage despite the establishment of the walk-in clinic. These possible explanations are not mutually exclusive and could all be playing a role in our results.

\section{Strengths and limitations}

Our study allowed the evaluation of the effectiveness of the walk-in clinic by using objective parameters of primary care quality. The strength of this study is that we evaluate an organisational-level intervention which evolved as response to the large-scale immigration in 2015 by means of a pre-post intervention study ${ }^{35}$ : exposure is measured in over two groups (an experimental group and a nonrandomised, non-concurrent control group), the health outcome is measured in both these groups (using ICD codes and flat-rate payment via German Diagnosis Related Groups) and a statistical comparison is made between the groups to assess potential relationships between exposure and outcome. In accordance with the one-group pre-post design, we evaluated the benefit of an intervention, that is, the introduction of the walk-in clinic. Using a quasi-experimental design, the study quantifies the effect of health service delivery designs among asylum seekers, adjusting for time trends and individual-level characteristics of the underlying population. By applying segmented regression as a tool to assess the impact of the organisational-level intervention, we could correct for preexisting non-stationary trends and thereby avoid several types of bias in analysis that may occur when assessing the impact of a policy change with routine longitudinal data. ${ }^{31}$ Furthermore, we considered the preventability of hospitalisation for ACS conditions for both children and adults in our study. This was done using two different lists targeting the specific age groups which thus avoided overestimation or underestimation of preventability. Due to the quasi-experimental nature of the study the sample size was out of our area of influence. We hence refrained from performing a power analysis, as the literature shows that post hoc power analysis should not be applied to the results of negative trials. It has shown to be inappropriate and potentially misleading. ${ }^{36-40}$ Instead, CIs were used to estimate the magnitude of effects that are statistically consistent with the data. ${ }^{36} 37$

A number of factors have to be considered when viewing the data and results. The average stay in the state reception- and registration centre is around 4 to 8 weeks before asylum seekers are transferred to a decentralised accommodation. Therefore, when exploring the preventability of hospitalisations among asylum seekers in the first weeks of arrival, there are various points of consideration. One of these points would be, that many of the influencing or underlying determinants of a medical condition - and the avoidance of this condition - may be located in a period before or during the process of migration, that is, the pre-migration or peri-migration period. Also, apart from health impacts arising on arrival, refugees and other migrants may display health indicators of their country of origin (incidence/ prevalence of illness, awareness/use of healthcare services) and present greater prevalence of illness resulting from torture, trauma, abuse and exposure during migration. ${ }^{41}$ Therefore, our results raise the question, if health services were not offered timely or if conditions accumulated in the previous stages of migration and could not be addressed earlier. Conceptually, circumstances of flight may have a strong influence on the development of ACS conditions, so that resulting hospitalisations may thus be results of flight and less of post-migration structures. Many factors and influences on hospitalisation for ACS conditions outside of the control of the ambulatory sector are difficult to adjust for ${ }^{32-44}$ and this presents the largest limitation for our study. Further points of consideration are the lack of both a concurrent control group and individuallevel data (such as nationality, migration route and social status), which could not be provided. Although routine 
data is prone to bias through coding behaviour, ${ }^{45}$ mostly standardised coding can be presumed due to both the German Hospital Reimbursement Act ('Krankenhausentgeltgesetz') and the fact, that there is no change in setting and thus limited possibility for the data to be affected. Another final issue to reflect on is the insufficient linkage with ambulatory care data from the reception centre, that is, lack of information on whether the patient was referred from outpatient care or self-referred. It was not possible to acquire this information due to data protection. However, if an exchange of information could be initiated, this could be a further relevant indicator in future research when measuring the effectiveness of the walk-in clinic.

\section{Possible implications for clinicians and policymakers and future research}

The walk-in clinic has functioned as a gate-opener for asylum seekers, however our results urge for further research. The introduction of a walk-in clinic in a reception centre offers low-threshold primary care for asylum seekers and is thus in line with components of primary healthcare service delivery models for refugees in resettlement countries that have previously been described in literature $^{46}$ and which have been effective in improving access, quality and coordination of care. It fulfils various aspects of this criteria by being accessible (the underlying measures hereby being: availability, affordability, appropriateness) and by using strategies to enhance access, such as including multidisciplinary staff (doctors, nurses, bilingual staff, interpreters). In light of the heterogenic organisation of access primary care for reception centres, further evaluation of the performance of walk-in clinics is required to establish a solid evidence-base for their effects of health outcomes, although the model in principle covers many aspects that have been shown to be effective in improving the performance parameters. Using the indicator ACS hospitalisations for measuring the availability and quality of ambulatory care among asylum seekers at a later stage, that is, after transfer to districts and communities, may be less prone to residual confounding by unmeasured pre-migration and peri-migration factors. Further, differences in flight conditions between cohorts of asylum seekers should be also captured in future studies, as these may affect ACS hospitalisations in countries of destination. Finally, additional ambulatory care data from the reception centre on whether or not a patient was referred, including time since arrival to the centre, could establish a further relevant indicator in future research on the impact of the walk-in clinic on hospitalisation for ACS conditions.

\section{CONCLUSION}

A walk-in clinic in reception centres may be effective in reducing ACS hospitalisations among asylum seekers, but our study could not prove evidence for a measurable impact on this outcome after full adjustment for time trends, age, sex and admission quarter. This study shows the need for further research with control design, so that the discussed limitations and confounders can be eliminated and stronger evidence can be established.

\section{Author affiliations}

${ }^{1}$ Department of General Practice and Health Services Research, Heidelberg University Hospital, Heidelberg, Germany

${ }^{2}$ Institute of General Practice and Family Medicine, Ludwig Maximilians University Munich, Munich, Germany

${ }^{3}$ Department of Population Medicine and Health Services Research, School of Publilc Health, Bielefeld University, Bielefeld, Germany

Twitter Kayvan Bozorgmehr @respond_study

Acknowledgements The authors thank Heidelberg University Hospital's patient administration for the support in data management and data provision.

Contributors Conceived the study: KB. Data analysis: $\mathrm{CL}, \mathrm{KB}$. Writing of first draft: KB, CL. Writing of subsequent drafts: KB, CL. All authors have approved and contributed to the final written manuscript.

Funding This study was part of the BMBF-funded project RESPOND ('Improving Regional Health System Responses to the challenge of forced migration through tailored interventions for asylum-seekers and refugees'). The last author received financial support by the Federal Ministry of Research and Education (BMBF) in the scope of the research programme 'Strukturaufbau in der Versorgungsforschung' (grant number: FKZ 01GY1611). We acknowledge financial support by Deutsche Forschungsgemeinschaft and Ruprecht-Karls-Universität Heidelberg within the funding programme Open Access Publishing.

Competing interests $\mathrm{KB}$ was actively involved in designing and setting-up the walk-in clinic. KB functions (among others) as coordinator for primary care related aspects of the walk-in clinic for the University Hospital Heidelberg, CL was involved in the process of the establishment of the walk-in clinic as a member of the Students4PHV-Project Heidelberg.

Patient consent for publication Not required.

Ethics approval The study was approved by the ethical committee of the Medical Faculty of the University of Heidelberg prior to onset of the study (Ethical approval number S-061/2016).

Provenance and peer review Not commissioned; externally peer reviewed. Data availability statement Data are available upon reasonable request.

Open access This is an open access article distributed in accordance with the Creative Commons Attribution Non Commercial (CC BY-NC 4.0) license, which permits others to distribute, remix, adapt, build upon this work non-commercially, and license their derivative works on different terms, provided the original work is properly cited, appropriate credit is given, any changes made indicated, and the use is non-commercial. See: http://creativecommons.org/licenses/by-nc/4.0/.

ORCID iD

Celina Lichtl http://orcid.org/0000-0002-7369-8695

\section{REFERENCES}

1 Correa-Velez I, Ansari Z, Sundararajan V, et al. A six-year descriptive analysis of hospitalisations for ambulatory care sensitive conditions among people born in refugee-source countries. Popul Health Metr 2007;5:9.

2 Ansari Z, Laditka JN, Laditka SB. Access to health care and hospitalization for ambulatory care sensitive conditions. Med Care Res Rev 2006;63:719-41.

3 Billings J, Zeitel L, Lukomnik J, et al. Impact of socioeconomic status on hospital use in New York City. Health Aff 1993;12:162-73.

4 Burgdorf F, Sundmacher L. Potentially avoidable hospital admissions in Germany: an analysis of factors influencing rates of ambulatory care sensitive hospitalizations. Deutsches Ärzteblatt International 2014;111:215-23.

5 Bozorgmehr K, Razum O. Effect of restricting access to health care on health expenditures among Asylum-Seekers and refugees: a quasi-experimental study in Germany, 1994-2013. PLoS One 2015;10:e0131483. 
6 Bozorgmehr K, Nöst S, Thaiss HM, et al. Die gesundheitliche Versorgungssituation von Asylsuchenden. Bundesgesundheitsblatt Gesundheitsforschung Gesundheitsschutz 2016;59:545-55.

7 Priebe S, Sandhu S, Dias S, et al. Good practice in health care for migrants: views and experiences of care professionals in 16 European countries. BMC Public Health 2011;11:187.

8 Langlois EV, Haines A, Tomson G, et al. Refugees: towards better access to health-care services. Lancet 2016;387:319-21.

9 Straßner C, Gewalt SC, Becker von Rose P, et al. Quality circles to identify barriers, facilitating factors, and solutions for high-quality primary care for asylum seekers. BJGP Open 2017;1.

10 Wahedi K, Nöst S, Bozorgmehr K. Die Gesundheitsuntersuchung von Asylsuchenden: Eine bundesweite analyse Der Regelungen in Deutschland. Bundesgesundheitsblatt Gesundheitsforschung Gesundheitsschutz 2017;60:108-17.

11 Federal Office for Migration and Refugees, Das Bundesamt in Zahlen. Asyl, migration und integration. Nürnberg, Germany: Federal Office for Migration and Refugees, 2015.

12 Bozorgmehr K, Mohsenpour A, Saure D, et al. Systematische Übersicht und „Mapping“ empirischer Studien des

Gesundheitszustands und der medizinischen Versorgung von Flüchtlingen und Asylsuchenden in Deutschland (1990-2014). Bundesgesundheitsblatt Gesundheitsforschung Gesundheitsschutz 2016;59:599-620.

13 Schneider C, Joos S, Bozorgmehr K. Disparities in health and access to healthcare between asylum seekers and residents in Germany: a population-based cross-sectional feasibility study. BMJ Open 2015;5:e008784.

14 Hörnle M. Die ersten Flüchtlinge sind Im Patrick Henry village eingezogen, 2014.

15 Teufert T. Flüchtlinge in Patrick Henry village: 2600 Bedürftige und kein einziger Sozialarbeiter, 2015.

16 Amt für Öffentlichkeitsarbeit Presse- und Informationsdienst der Stadt Heidelberg. Menschen auf der Flucht - Heidelberg setzt auf dezentrale Unterbringung und Integration in den Stadtteilenin Presseinformation der Stadt Heidelberg. Heidelberg, Germany, 2018: 3.

17 Statistisches Landesamt Baden-Württemberg. Asylbewerberzugang nach Baden-Württemberg und Deutschland monatlich. Stuttgart, Germany.: Statistisches Langdesamt Baden-Württemberg, 2018.

18 Rübsam-Brodkorb D, Bird J. Erweitertes medizinisches Angebot für Flüchtlinge im Patrick Henry Village. Universitätsklinikum Heidelberg, Pressestelle: Heidelberg, 2016.

19 Nikendei Cet al. Development and implementation of an outpatient clinic at an initial reception centre for asylum seekers in the German federal state of Baden-Wuerttemberg. Zeitschrift für Evidenz, Fortbildung und Qualität im Gesundheitswesen 2017;126:31-42.

20 Campbell M, Katikireddi SV, Hoffmann T, et al. TIDieR-PHP: a reporting guideline for population health and policy interventions. BMJ 2018;361.

21 Anderson P, Craig E, Jackson G, et al. Developing a tool to monitor potentially avoidable and ambulatory care sensitive hospitalisations in New Zealand children. N Z Med J 2012;125:25-37.

22 Becker DJ, Blackburn JL, Kilgore ML, et al. Continuity of insurance coverage and ambulatory care-sensitive hospitalizations/ED visits: evidence from the children's health insurance program. Clin Pediatr 2011;50:963-73.

23 Casanova C, Colomer C, Starfield B. Pediatric hospitalization due to ambulatory care-sensitive conditions in Valencia (Spain). Int J Qual Health Care 1996;8:51-9.

24 Flores Get al. Keeping children with asthma out of hospitals: parents' and physicians' perspectives on how pediatric asthma hospitalizations can be prevented. Pediatrics 2005;116:957-65.

25 Jaeger MW, Ambadwar PB, King AJ, et al. Emergency care of children with ambulatory care sensitive conditions in the United States. J Emerg Med 2015;49:729-39.
26 Lu S, Kuo DZ. Hospital charges of potentially preventable pediatric hospitalizations. Acad Pediatr 2012;12:436-44.

27 Prezotto KH, Chaves MMN, Mathias TAdeF. Hospital admissions due to ambulatory care sensitive conditions among children by age group and health region. Rev Esc Enferm USP 2015;49:44-53.

28 Lichtl C, Lutz T, Szecsenyi J, et al. Differences in the prevalence of hospitalizations and utilization of emergency outpatient services for ambulatory care sensitive conditions between asylum-seeking children and children of the general population: a cross-sectional medical records study (2015). BMC Health Serv Res 2017;17:731.

29 Sundmacher L, Fischbach D, Schuettig W, et al. Which hospitalisations are ambulatory care-sensitive, to what degree, and how could the rates be reduced? results of a group consensus study in Germany. Health Policy 2015;119:1415-23.

30 Petrie A, Sabin C. Medical statistics at a glance. In: At a glance. 3rd edn. Oxford, England: John Wiley \& Sons, Ltd, 2009.

31 Lagarde M. How to do (or not to do). Assessing the impact of a policy change with routine longitudinal data. Health Policy Plan 2012;27:76-83.

32 Mipatrini D, Addario SP, Bertollini R, et al. Access to healthcare for undocumented migrants: analysis of avoidable hospital admissions in Sicily from 2003 to 2013. Eur J Public Health 2017;27:459-64.

33 Norredam M, Mygind A, Nielsen AS, et al. Motivation and relevance of emergency room visits among immigrants and patients of Danish origin. Eur J Public Health 2007:17:497-502.

34 Hargreaves S, Friedland JS, Gothard P, et al. Impact on and use of health services by international migrants: questionnaire survey of inner city London A\&E attenders. BMC Health Serv Res 2006;6:153.

35 Thiese MS. Observational and interventional study design types; an overview. Biochem Med 2014;24:199-210.

36 Levine M, Ensom MH. Post hoc power analysis: an idea whose time has passed? Pharmacotherapy 2001;21:405-9.

37 Goodman SN, Berlin JA. The use of predicted confidence intervals when planning experiments and the misuse of power when interpreting results. Ann Intern Med 1994;121:200-6.

38 Smith AH, Bates MN. Confidence limit analyses should replace power calculations in the interpretation of epidemiologic studies. Epidemiology 1992;3:449-52.

39 Hoenig J, Heisey D. The abuse of power: the pervasive fallacy of power calculations for data analysis. The American Statistician 2001;55:19-24.

40 Greenland S. On SAMPLE-SIZE and power calculations for studies using confidence intervals. Am J Epidemiol 1988;128:231-7.

41 Gushulak BD, MacPherson DW. The basic principles of migration health: population mobility and gaps in disease prevalence. Emerg Themes Epidemiol 2006;3:3.

42 Giuffrida A, Gravelle H, Roland M. Measuring quality of care with routine data: avoiding confusion between performance indicators and health outcomes. BMJ 1999;319:94-8.

43 Yun K, Hebrank K, Graber LK, et al. High prevalence of chronic noncommunicable conditions among adult refugees: implications for practice and policy. J Community Health 2012;37:1110-8.

44 Trachtenberg AJ, Dik N, Chateau D, et al. Inequities in ambulatory care and the relationship between socioeconomic status and respiratory hospitalizations: a population-based study of a Canadian City. Ann Fam Med 2014;12:402-7.

45 Freund T, Heller G, Szecsenyi J. Hospitalisations for ambulatory care sensitive conditions in Germany. Zeitschrift für Evidenz, Fortbildung und Qualität im Gesundheitswesen 2014;108:251-7.

46 Joshi C, Russell G, Cheng I-H, et al. A narrative synthesis of the impact of primary health care delivery models for refugees in resettlement countries on access, quality and coordination. Int $J$ Equity Health 2013;12:88. 